Article

\title{
3-(Methoxycarbonylmethylene)isobenzofuran-1-imines as a New Class of Potential Herbicides
}

Fabrizio Araniti ${ }^{1}$, Raffaella Mancuso ${ }^{2, *}$, Ida Ziccarelli ${ }^{2}$, Francesco Sunseri ${ }^{1}$, Maria Rosa Abenavoli ${ }^{1, *}$ and Bartolo Gabriele ${ }^{2, *}$

1 Dipartimento AGRARIA, Università Mediterranea di Reggio Calabria, Reggio Calabria 89124, Italy

2 Dipartimento di Chimica e Tecnologie Chimiche, Università della Calabria, Via P. Bucci 12/C, Arcavacata di Rende (Cosenza) 87036, Italy

* Authors to whom correspondence should be addressed; E-Mails: raffaella.mancuso@unical.it (R.M.); mrabenavoli@unirc.it (M.R.A.); bartolo.gabriele@unical.it (B.G.); Tel.: +39-0984-492-816 (R.M.); +39-0965-324-077 (M.R.A.); +39-0984-492-813 (B.G.); Fax: +39-0984-492-044 (R.M. \& B.G.); +39-0965-311-092 (M.R.A.).

Received: 23 April 2014; in revised form: 30 May 2014 / Accepted: 9 June 2014 /

Published: 18 June 2014

Abstract: A novel class of potential herbicides, the 3-(methoxycarbonylmethylene) isobenzofuran-1-imines, has been discovered. The herbicidal activity has been tested on two particular molecules, $(E)$-methyl 2-[3-(butylimino)isobenzofuran-1(3H)-ylidene]acetate (1) and (E)-methyl 2-phenyl-2-[3-(phenylimino)isobenzofuran-1(3H)-ylidene]acetate (2), prepared by palladium-catalyzed oxidative carbonylation of 2-alkynylbenzamides. Both compounds 1 and $\mathbf{2}$ showed a strong phytotoxic effect on both shoot and root systems of Arabidopsis thaliana. The effects observed on the shoot were similar for both molecules, but while compound $\mathbf{1}$ showed a stronger effect on root parameters (such as primary root length, root hair and density, showing lower $\mathrm{ED}_{50}$ values), compound $\mathbf{2}$ caused important malformations in root morphology. Our results indicate that these molecules are very promising synthetic herbicides.

Keywords: Arabidopsis thaliana; carbonylation; isobenzofuranimines; shoot parameters; root morphology; phytotoxicity 


\section{Introduction}

In modern agriculture, the control of weeds is one of the goals to maximize crop yield and quality. Weeds compete with crops not only for edaphic resources such as water and nutrients, but also for space and sunlight. Moreover, many weeds are the hosts of a variety of pathogens such as viruses, fungi, insects, which in turn can determine the occurrence and spread of plant diseases and insect pests in crops. Nowadays, herbicides play a pivotal role in management strategies in weed control and billions of dollars are spent every year to cope with this problem.

Since the 1940s, when the first synthetic chemicals were introduced for this purpose, the agrochemical industry has successfully developed a wide array of herbicides, characterized by various chemical structures and modes of action [1]. However, in recent decades, the indiscriminate use of chemicals has caused the development of herbicide-resistant weeds [2]. Ryan was the first to describe simazine resistance in Senecio vulgaris [3]. Later, it has been demonstrated that chlorsulfuron, atrazine, diclofop-methyl, and paraquat caused a significant change in weed communities and consequently the evolution of herbicide-resistant biotypes insensitive to herbicidal treatments [4]. Since 1990, weed-resistance to most herbicide classes in almost 100 weed species has been described [4]. Therefore, the research aimed at developing new synthetic herbicides, with novel modes of action compared to the currently used herbicides, is becoming more and more important. Although this approach is an useful strategy for weed management, especially in recent years in which the number of patents on herbicides has dramatically decreased, repeated application of effective herbicides with the same mode of action continues to be the greatest risk factor for herbicide-resistance evolution [5]. That is why the development of new herbicides with multiple modes of action, or of suitable mixtures of herbicides able to simultaneously affect different targets, is becoming of primary importance in the current weed management research [6].

In this paper, the biological activity of two synthetic 3-(methoxycarbonylmethylene)isobenzofuran-1imine derivatives, $(E)$-methyl 2-[3-(butylimino)isobenzofuran-1(3H)-ylidene]acetate (1) and $(E)$-methyl 2-phenyl-2-[3-(phenylimino)isobenzofuran-1(3H)-ylidene]acetate (2), on plant growth and metabolism of Arabidopsis thaliana has been evaluated. These molecules, synthetized from simple substrates by a catalytic carbonylation approach, showed significant and very promising potential herbicidal activity.

\section{Results and Discussion}

\subsection{Synthesis of 3-(Methoxycarbonylmethylene)isobenzofuran-1-imines $\mathbf{1}$ and $\mathbf{2}$}

(E)-Methyl 2-[3-(butylimino)isobenzofuran-1(3H)-ylidene]acetate (1) and (E)-methyl 2-phenyl-2[3-(phenylimino)isobenzofuran-1(3H)-ylidene]acetate (2) were prepared by $\mathrm{PdI}_{2} / \mathrm{KI}$-catalyzed oxidative carbonylation [7] of $N$-butyl-2-ethynylbenzamide and $N$-phenyl-2-(2-phenylethynyl)benzamide, respectively, carried out in a trimethyl orthoformate $/ \mathrm{MeOH}$ mixture $(2: 1 \mathrm{v} / \mathrm{v})$ at $100{ }^{\circ} \mathrm{C}$ and under $40 \mathrm{~atm}$ of a 4:1 mixture of CO-air, in the presence of $2 \mathrm{~mol} \%$ of $\mathrm{PdI}_{2}$ and $20 \mathrm{~mol} \%$ of KI, according to Scheme 1 (anionic iodide ligands are omitted for clarity). The use of trimethyl orthoformate as co-solvent was necessary in order to avoid substrate hydrolysis under the reaction conditions. The process occurs through anti 5-exo-dig $O$-cyclization, ensuing from intramolecular nucleophilic attack by the carbonyl oxygen on triple bond coordinated to $\mathrm{PdI}_{2}$, followed by carbon monoxide insertion and 
nucleophilic displacement by $\mathrm{MeOH}$ (Scheme 1). The $\mathrm{Pd}(0)$ species formed in the nucleophilic displacement step is then reoxidized back to $\mathrm{PdI}_{2}$ by the action of $\mathrm{O}_{2}$ according to a well-known mechanism [7-9].

Scheme 1. Synthesis of $(E)$-methyl 2-[3-(butylimino)isobenzofuran-1(3H)-ylidene]acetate (1) and (E)-methyl 2-phenyl-2-[3-(phenylimino)isobenzofuran-1(3H)-ylidene]acetate (2) by $\mathrm{PdI}_{2} / \mathrm{KI}$-catalyzed oxidative carbonylation of $\mathrm{N}$-butyl-2-ethynylbenzamide and $N$-phenyl-2-(2-phenylethynyl)benzamide, respectively (anionic iodide ligands are omitted for clarity).
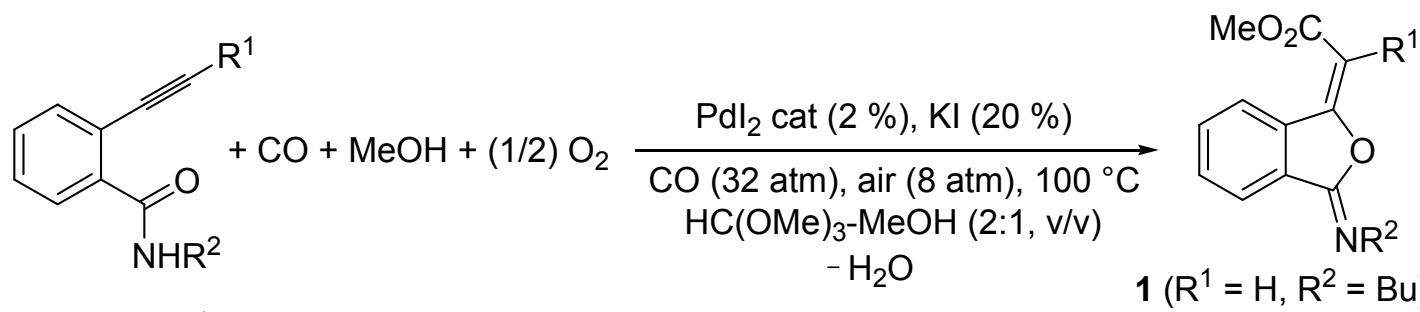

$$
\mathrm{Pdl}_{2} \backslash
$$

$2\left(R^{1}=R^{2}=P h\right): 55 \%$
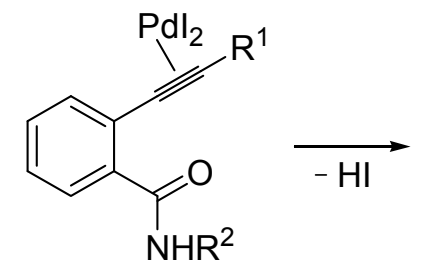

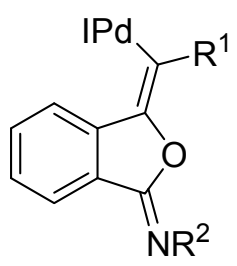

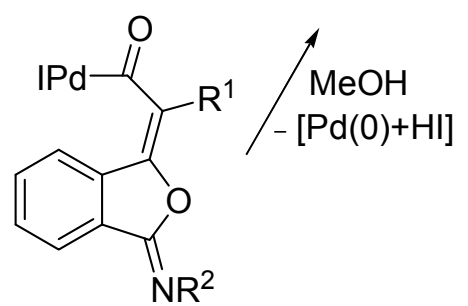

$$
\mathrm{Pd}(0)+2 \mathrm{HI}+(1 / 2) \mathrm{O}_{2} \longrightarrow \mathrm{Pdl}_{2}+\mathrm{H}_{2} \mathrm{O}
$$

\subsection{Effects of 3-(Methoxycarbonylmethylene)isobenzofuran-1-imines $\mathbf{1}$ and $\mathbf{2}$ on A. thaliana Shoot}

\section{Morpho-Physiological Parameters}

To verify if compounds $\mathbf{1}$ and $\mathbf{2}$ could be active as potential new herbicides, we tested them in a rather broad range of concentrations $(50-400 \mu \mathrm{M})$, as reported in the literature for other newly synthesized molecules [10]. Both molecules $\mathbf{1}$ and $\mathbf{2}$ caused a strong inhibitory effect on all morpho-physiological parameters in A. thaliana seedlings. In particular, shoot fresh weight (SFW) was significantly affected by 1 already at the lowest concentration tested $(50 \mu \mathrm{M})$ (Figure 1), whereas 2 caused a significant inhibition at $100 \mu \mathrm{M}$ (Figure 2). The complete inhibition was reached at the highest concentration tested $(400 \mu \mathrm{M})$ with both molecules (Figures 1 and 2 ).

The non-linear regression fits of the SFW dose-response curves of $\mathbf{1}$ and $\mathbf{2}$ were characterized by a high statistical significance $(p \leq 0.001)$, but differed significantly in $\mathrm{ED}_{50}$ values $(20 \mu \mathrm{M} v s .70 \mu \mathrm{M}$, respectively), confirming the higher inhibitory activity of $\mathbf{1}$ compared to $\mathbf{2}$ (data not shown). A similar trend of inhibition on Leaf Area (LA) and Leaf Number (LN) parameters was observed (Figures 1 and 2).

The simultaneous decrease in SFW, LA and LN suggested a more complex effect induced by both isobenzofuranimines $\mathbf{1}$ and $\mathbf{2}$ on the overall plant metabolism. Indeed, both molecules reduced, with a similar trend, the pigments content (Figures 1 and 2). In particular, chlorophyll $a$ and $b$ content decreased in a dose-dependent manner, whereas the carotenoid content was decreased at all tested concentrations (Figures 1 and 2). Previous studies already demonstrated a reduction in chlorophyll $a$ 
and $b$ contents coupled with a chlorotic appearance in the leaves of plants treated with phenolic acids $[11,12]$.

Figure 1. Morpho-physiological parameters of $A$. thaliana seedlings treated with different concentrations of compound 1: Shoot Fresh Weight (SFW), Leaf Number (LN), Leaf Area (LA), pigments content, Carotenoids:Chlorophyll Ratio and MDA content. Different letters along the curves indicate significant differences at $p \leq 0.05$. All data were analyzed by ANOVA, applying Tukey's and Tamhane's T2 tests for homoscedastic and heteroscedastic parameters, respectively $(N=5)$.

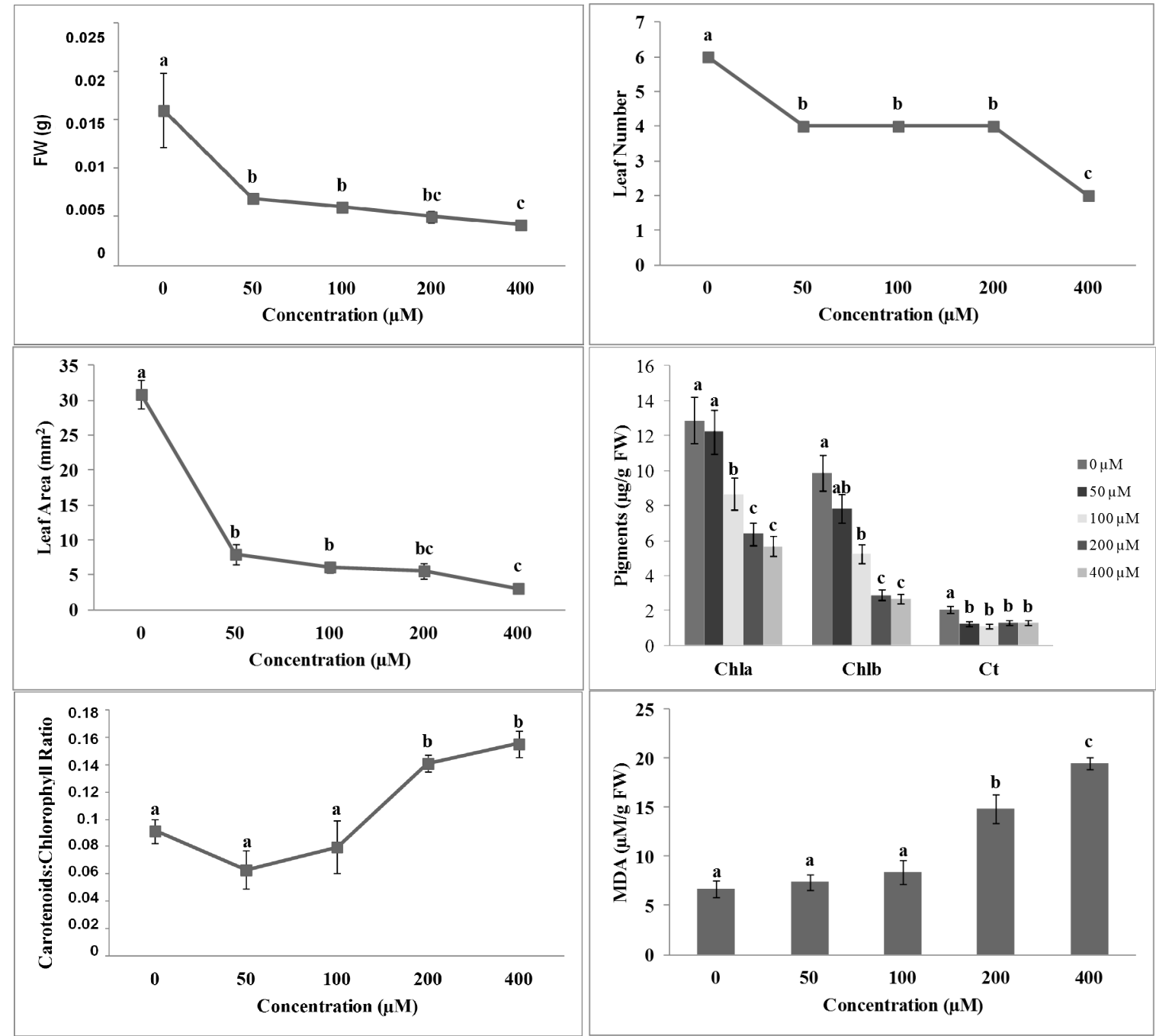

Recently, similar results were also reported on Arabidopsis plants treated with citral [13], a volatile component of many aromatic plants [14]. In particular, the authors observed that citral treatment caused strong inhibitory effects on several photosynthetic parameters, such as the pigment content and fluorescence of the chlorophyll $a$. The carotenoids/chlorophyll ratio significantly increased upon treatment with 200 and $400 \mu \mathrm{M}$ of both molecules. A similar trend was followed by the malonyldialdehyde (MDA) content (Figures 1 and 2). As reported by Filella et al. [15], carotenoids/chlorophyll ratio index increased under abnormal or limiting conditions. The change in ratio index could be due to an increase in carotenoids content, indicating an activation of the 
photoprotection mechanism by plants. Conversely, it could be due to a reduction in chlorophylls content, meaning the occurrence of photodegradation phenomena.

Figure 2. Morpho-physiological parameters of $A$. thaliana seedlings treated with different concentrations of the compound 2: Shoot Fresh Weight (SFW), Leaf Number (LN), Leaf Area (LA), pigments content, Carotenoids:Chlorophyll Ratio and MDA content. Different letters along the curves indicate significant differences at $p \leq 0.05$. All data were analyzed by ANOVA, applying Tukey's and Tamhane's T2 tests for homoscedastic and heteroscedastic parameters, respectively $(N=5)$.

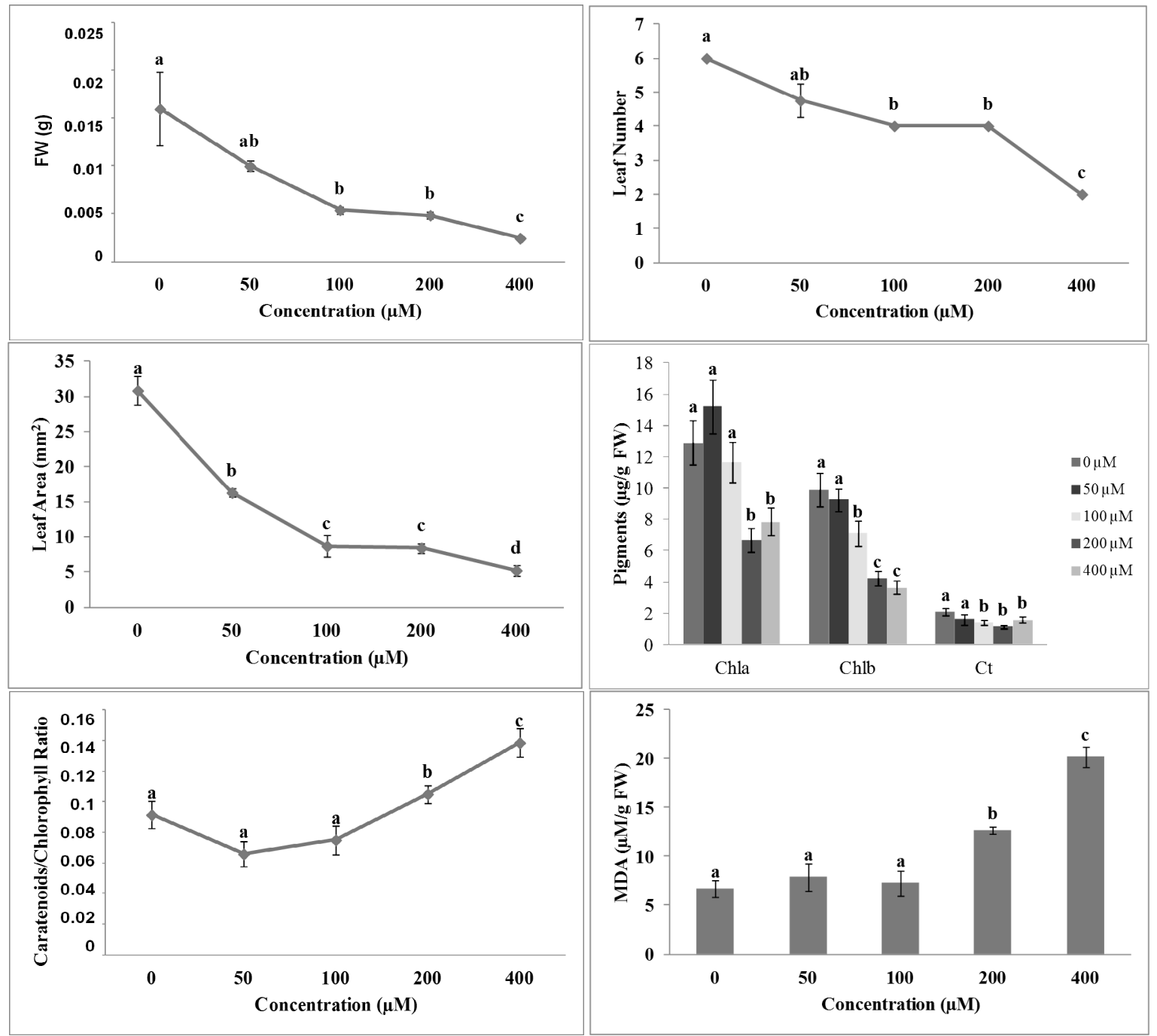

Under our experimental conditions, the change in carotenoids/chlorophyll ratio index appeared to be caused by a reduction in chlorophyll $a$ and $b$ content accompanied by an increase in MDA, suggesting that the photodegradation could be attributable to oxidation damages. A similar effect was observed on Arabidopsis plants treated with 2-3H-benzoxazolinone (BOA) [16]: an increase in lipid peroxidation was accompanied by a proteins and pigments degradation, which has been associated with a reduction in stability of the antenna complex, as also suggested by Liu et al. [17]. 


\subsection{Effects of Isobenzofuranimines $\mathbf{1}$ and $\mathbf{2}$ on Root Morphology of A. thaliana}

The root morphology of $A$. thaliana seedlings was strongly affected by both isobenzofuranimines $\mathbf{1}$ and 2 (Figures 3 and 4). Both molecules were effective at the lowest concentration tested, causing a reduction in primary root length by $75 \%$ and $45 \%$ for molecule 1 and 2 , respectively (Figures 3 and 4).

Figure 3. Dose-response curves of root morphology of $A$. thaliana seedlings treated with compound 1: primary root length (PRL), number of lateral root (NLR), root hair density (RHD) and root hair length (RHL). Data are expressed as percentage of the control. Different letters along the curves indicate significant differences at $p \leq 0.05$. All data were analyzed by ANOVA, applying Tukey's and Tamhane's T2 tests for homoscedastic and heteroscedastic parameters, respectively $(N=5)$.

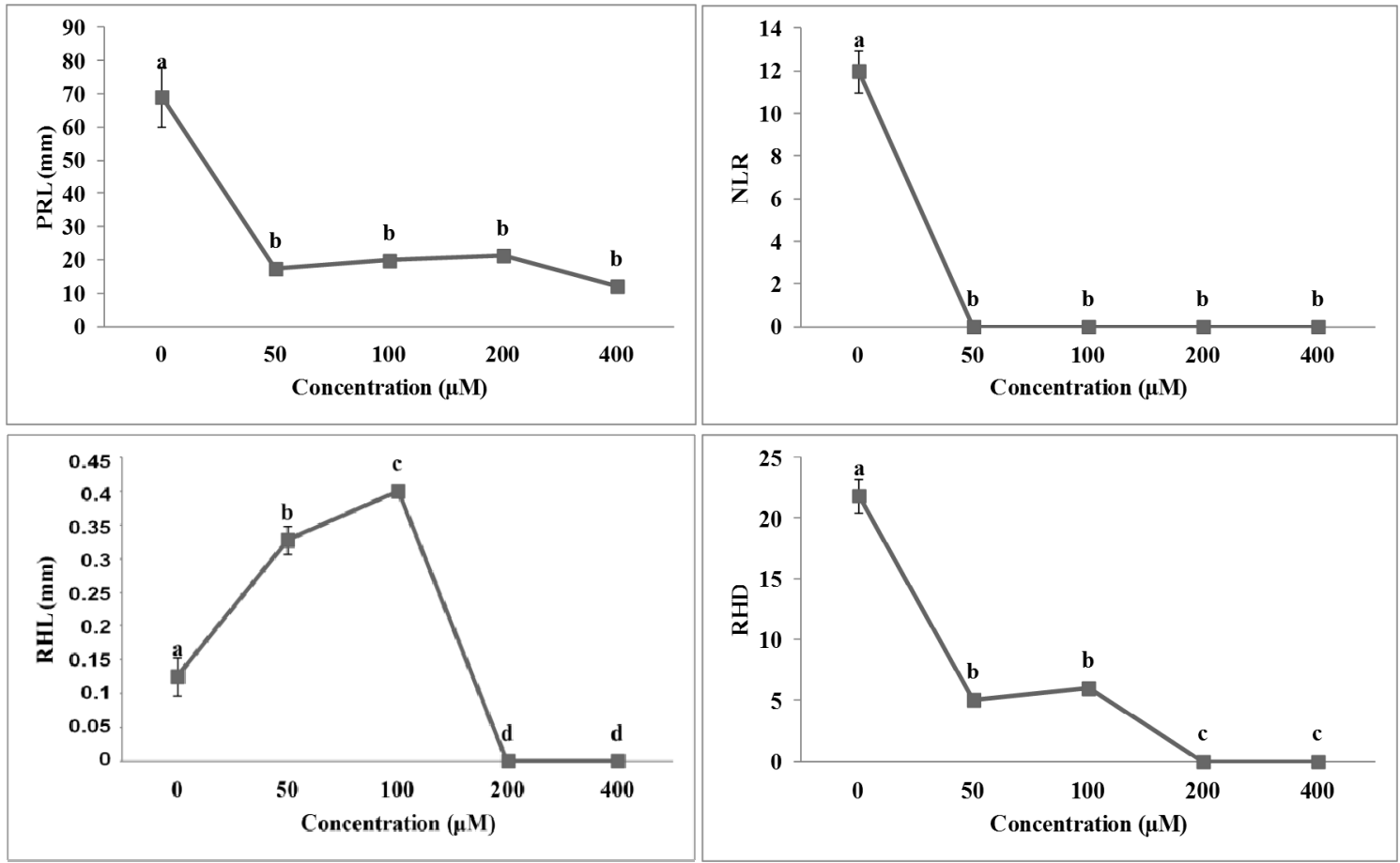

On the other hand, compounds $\mathbf{1}$ and $\mathbf{2}$ had a contrasting effect on NLR. In particular, seedlings treated with 1 showed a lack in lateral roots formation already at the lowest concentration, whereas those treated with 2 showed a significant stimulation (hormetic effect) between 100 and $200 \mu \mathrm{M}$ concentrations range, reaching the complete inhibition only at $400 \mu \mathrm{M}$ (Figure 3). Interestingly, both the stimulatory and inhibitory effects were also observed on both root hairs parameters (RHD and RHL). In particular, at 50 and $100 \mu \mathrm{M}$ concentrations, molecule 1 caused a reduction of root hair density (RHD), which was accompanied by an increase in root hair length (RHL), whereas higher concentrations completely inhibited both parameters (Figure 3). On the other hand, molecule 2 significantly stimulated the RHL parameter at all the concentrations tested (Figure 4), whereas the RHD significantly increased up to $200 \mu \mathrm{M}$ concentration and then collapsed at the highest concentration (Figure 4). The non-linear regression fit of data and the comparison of the $\mathrm{ED}_{50}$ values (Table 1) pointed out a higher inhibitory effect of isobenzofuranimine $\mathbf{1}$ compared to $\mathbf{2}$, in all the root 
parameters, already at lower concentrations (Table 1). Conversely, compound $\mathbf{2}$ was able to stimulate NLR and RHD parameters at lower concentrations than 1, which in its turn was able to stimulate RHL.

Figure 4. Dose-response curves of root morphology of $A$. thaliana seedlings treated for 10 days with compound 2: primary root length (PRL), number of lateral root (NLR), root hair density (RHD) and root hair length (RHL). Data are expressed as percentage of the control. Different letters along the curves indicate significant differences at $p \leq 0.05$ ). All data were analyzed by ANOVA, applying Tukey's and Tamhane's T2 tests for homoscedastic and heteroscedastic parameters, respectively $(N=5)$.

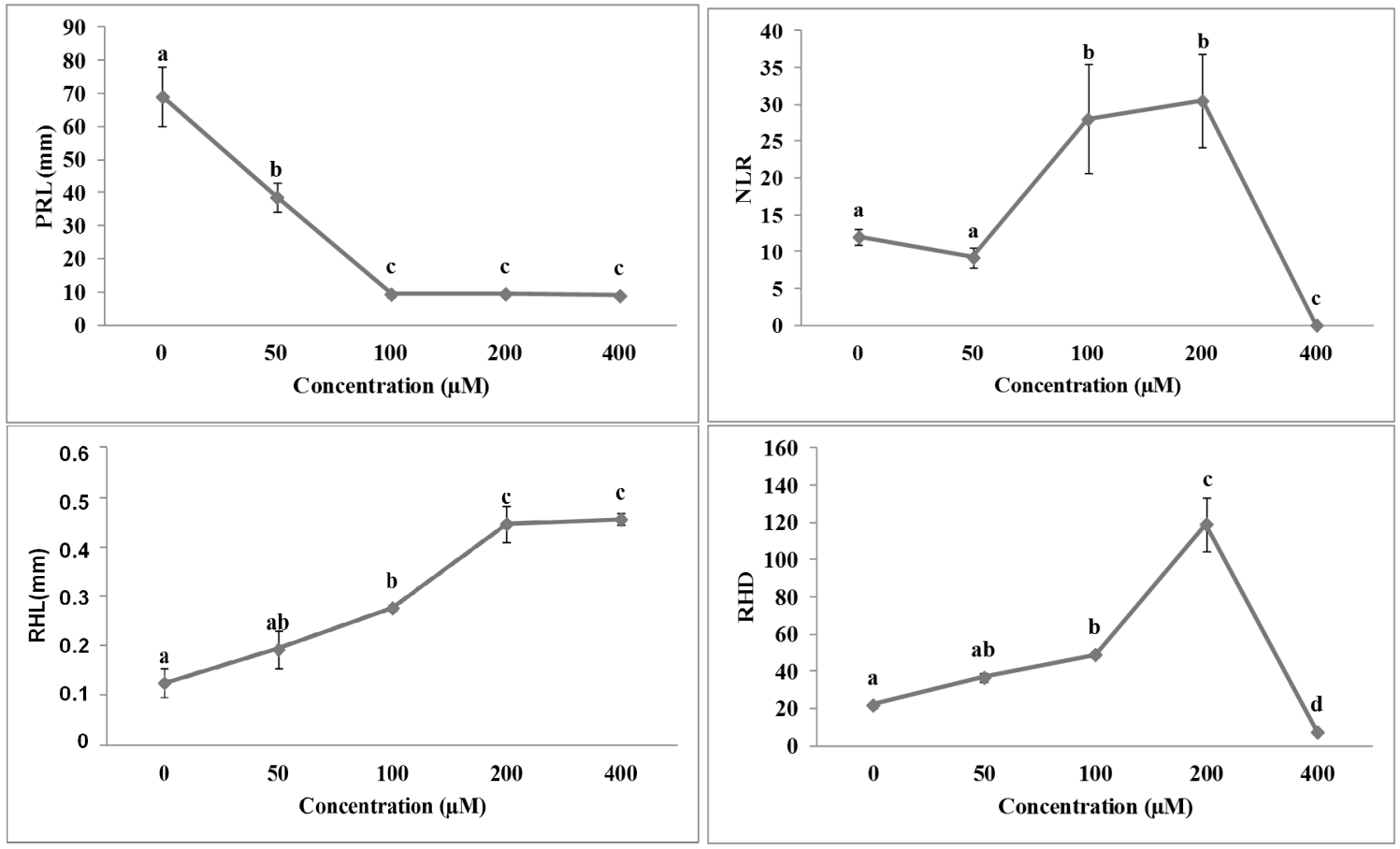

Table 1. $\mathrm{ED}_{50}(\mu \mathrm{M})$ values and stimulatory concentrations $(\mu \mathrm{M})$ of primary root length (PRL), number of lateral root (NLR), root hair density (RHD) and root hair length (RHL) of $A$. thaliana estimated by the log-logistic equations in response to different concentrations of compounds 1 and 2. Data from Figures 1-4. Different letters along the columns, for each parameter, indicate significant differences at $p<0.05$ (Tukey's test). Values within the brackets indicated the standard deviation $(N=5)$. All the dose-response curves pointed out a significance level of $p<0.001$.

\begin{tabular}{ccccc}
\hline & \multicolumn{4}{c}{ ED $_{\mathbf{5 0}}(\boldsymbol{\mu M})$} \\
\cline { 2 - 5 } Isobenzofuranimine & PRL & NLR & RHD & RHL \\
\hline $\mathbf{1}$ & $28.5( \pm 0.46)^{\mathrm{a}}$ & $9.73 * \mathrm{e}-13( \pm 0.0001)^{\mathrm{a}}$ & $20.46( \pm 1.5)^{\mathrm{a}}$ & $119.87( \pm 11.78)^{\mathrm{a}}$ \\
$\mathbf{2}$ & $52.5( \pm 4.8)^{\mathrm{b}}$ & $225.06( \pm 5.29)^{\mathrm{b}}$ & $397.1( \pm 0.78)^{\mathrm{b}}$ & $\mathrm{ND}$ \\
\cline { 2 - 5 } & $\mathrm{5}$ & \multicolumn{4}{c}{ Stimulation $(\boldsymbol{\mu M})$} \\
$\mathbf{1}$ & $\mathrm{ND}$ & $\mathrm{ND}$ & $\mathrm{ND}$ & $18.16( \pm 0.21)^{\mathrm{a}}$ \\
$\mathbf{2}$ & $\mathrm{ND}$ & $28.66( \pm 5.3)$ & $60.97( \pm 0.04)$ & $108.2( \pm 2.1)^{\mathrm{b}}$ \\
\hline
\end{tabular}

Although similar in chemical structure, the two molecules induced contrasting effects on the root morphology and anatomy (compare Figures 5 and 6). In particular, seedlings treated with 
isobenzofuranimine 1, especially at high concentrations (200 and $400 \mu \mathrm{M})$, caused a strong reduction in root growth, accompanied by a lack in lateral roots and root hairs. Moreover, root deformations, mainly caused by not aligned cells, resulted evident (Figure 5). These effects are typically induced by okadaic acid and calyculin-A, protein-phosphatase inhibitors, which are able to block the root hair development, and severely affect the shape of the cells within the zone of elongation, inhibit root growth rates and change the root directional growth [18]. These negative modifications in root development are ascribable to the ability of these molecules to inhibit the dephosphorylation of phosphoproteins by members of the type-1 and -2A family of protein phosphatases [19,20], required for the cell-cycle progression and the control of microtubule reorganization during mitosis [21-23]. In addition, the lack in root hair development was constantly observed in seedlings treated with microtubules effectors [24,25], confirming the possibility that compound $\mathbf{1}$, at the concentrations of 200 and $400 \mu \mathrm{M}$, could indirectly interfere with the microtubule stability. Finally, it cannot be excluded that the hormonal imbalance could be responsible of the lack of lateral roots, as suggested by Ivanchenko et al. [26].

Figure 5. Root tip of $A$. thaliana grown in vitro and treated with different concentrations of compound 1. Note the lack of root hairs development at the highest concentrations. NB photos taken with different magnification.

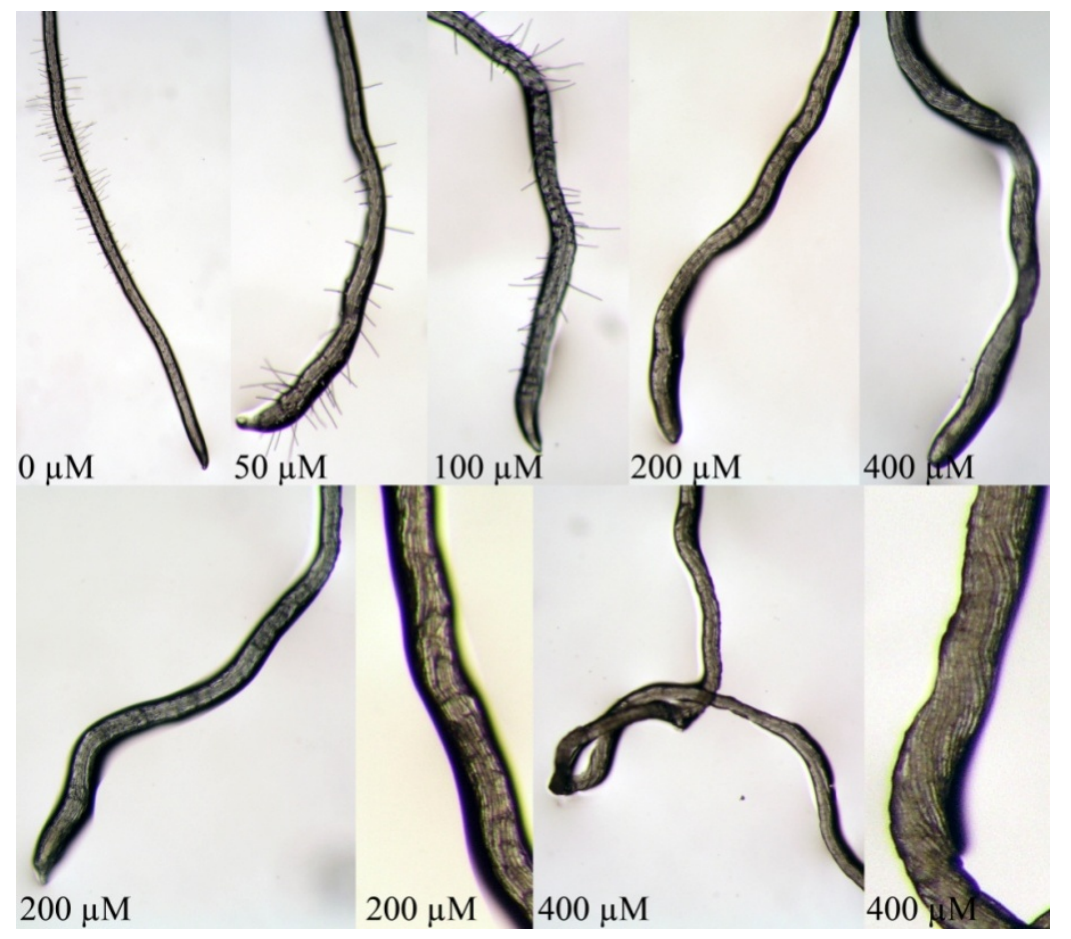

The morphological and anatomical effects observed upon treatment with isobenzofuranimine $\mathbf{2}$ are reported in Figure 6. Remarkably, the effects caused by this molecule were opposite with respect to those of compound 1. Indeed, seedlings treated with 100 and $200 \mu \mathrm{M}$ concentrations, showed an increase of the lateral roots number, length and density of root hairs, along with strong malformations mainly due to the growing fused or irregularly spaced lateral roots (Figure 6). Moreover, the distribution of lateral roots along the axes appeared to be rather grouped in clusters, losing the normal longitudinal positioning observable in the control (Figure 6). 
Figure 6. Root tip of $A$. thaliana grown in vitro and treated with different concentrations of compound 2. Note the root malformation and the stimulation of lateral roots and root hairs. NB photos taken with different magnification.

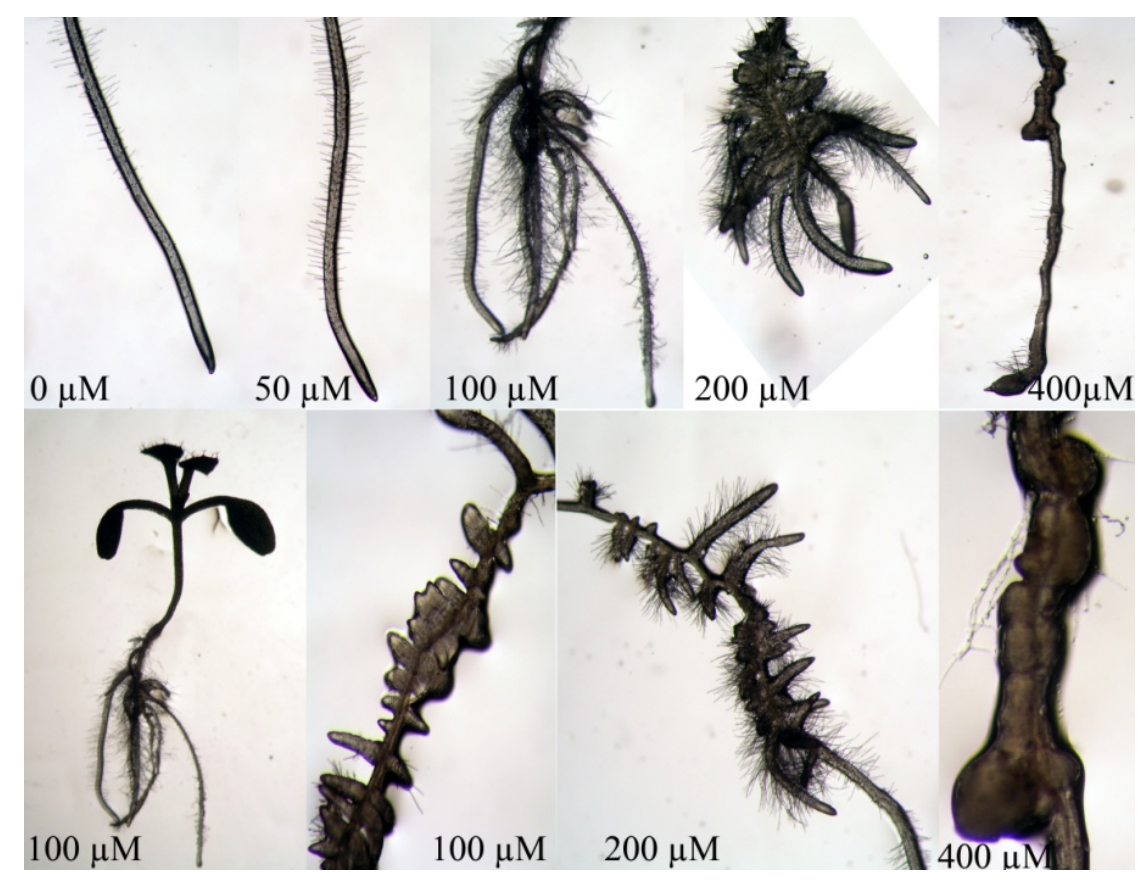

At the highest concentration $(400 \mu \mathrm{M})$, a strong swelling of the root tip was evident and, along root axes, an attempted differentiation of lateral roots, whose growth was blocked leading to primary root deformation. Similar results were also observed by Li et al. [27], when Arabidopsis seedlings were treated with 4-methylumbelliferone. An increased expression of two auxin efflux facilitator genes (PIN2 and PIN3) were observed together with a lack of response of the auxin receptor TIR1 and the key auxin biosynthetic gene YUCCA1. These results suggested that root branching stimulation could be due to a direct or indirect mediation of auxin redistribution, rather than auxin biosynthesis. Moreover, PIN proteins affected lateral root density and spacing. They observed in a triple PIN mutant the reduction of longitudinal lateral roots spacing. Furthermore, the increase in lateral root density was not accompanied by a concurrent increase in root length.

Accordingly to our results, Lakowski et al. [28] also observed a high number of fused lateral roots, which were separated into two distinct roots only on the tips, indicating that in triple PIN mutant the mechanisms leading to lateral inhibition of organ formation could be interrupted.

Further studies are needed to understand the mode of action of both molecules. Since an involvement of plant growth regulators have been hypothesized, the use of Arabidopsis mutants and/or auxin transport and biosynthesis inhibitors could help to better explain the isobenzofuranimine mode of action.

\section{Experimental}

\subsection{General Information}

Chemicals were purchased from Sigma-Aldrich Italia (Milano, Italy) and were used as such without further purification. Melting points were taken on a Reichert Thermovar apparatus and are uncorrected. 
${ }^{1} \mathrm{H}-\mathrm{NMR}$ and ${ }^{13} \mathrm{C}-\mathrm{NMR}$ spectra were recorded at $25{ }^{\circ} \mathrm{C}$ in $\mathrm{CDCl}_{3}$ solutions with a Bruker DPX Avance 300 spectrometer operating at $300 \mathrm{MHz}$ and $75 \mathrm{MHz}$, respectively, with $\mathrm{Me}_{4} \mathrm{Si}$ as internal standard. Chemical shifts $(\delta)$ and coupling constants $(J)$ are given in ppm and in Hz, respectively. IR spectra were taken with a JASCO FT-IR 4200 spectrometer. Mass spectra were obtained using a Shimadzu QP-2010 GC-MS apparatus at $70 \mathrm{eV}$ ionization voltage. Microanalyses were carried out with a Carlo Erba Elemental Analyzer Mod. 1106. All reactions were analyzed by TLC on silica gel $60 \mathrm{~F}_{254}$ (Merck) or on neutral alumina (Merck) and by GLC using a Shimadzu GC-2010 gas chromatograph and capillary columns with polymethylsilicone $+5 \%$ polyphenylsilicone as the stationary phase (HP-5). Column chromatography was performed on neutral alumina 90 (Merck, 70-230 mesh). Evaporation refers to the removal of solvent under reduced pressure.

\subsection{Preparation of Isobenzofuranimines $\mathbf{1}$ and $\mathbf{2}$ [29]}

A $250 \mathrm{~mL}$ stainless steel autoclave was charged in the presence of air with $\mathrm{PdI}_{2}(5.0 \mathrm{mg}$, $\left.1.39 \times 10^{-2} \mathrm{mmol}\right)$, KI $\left(23.0 \mathrm{mg}, 1.39 \times 10^{-1} \mathrm{mmol}\right)$ and a solution of $N$-butyl-2-ethynylbenzamide (141 mg, $0.70 \mathrm{mmol}$ ) or $N$-phenyl-2-(2-phenylethynyl)benzamide (208 $\mathrm{mg}, 0.70 \mathrm{mmol})$ in a $\mathrm{MeOH} / \mathrm{HC}(\mathrm{OMe})_{3}$ mixture [MeOH: $11.6 \mathrm{~mL} ; \mathrm{HC}(\mathrm{OMe})_{3}: 23.1 \mathrm{~mL}$ ]. The autoclave was sealed and, while the mixture was stirred, the autoclave was pressurized with $\mathrm{CO}$ (32 atm) and air (up to $40 \mathrm{~atm}$ ). After being stirred at $100{ }^{\circ} \mathrm{C}$ for the $15 \mathrm{~h}$, the autoclave was cooled, degassed and opened. The solvent was evaporated, and the residue purified by column chromatography on neutral alumina (eluent: 95:5 hexane/AcOEt) to give pure $(E)$-methyl 2-[3-(butylimino)isobenzofuran-1(3H)-ylidene]acetate 1 (127.3 mg, 70\%) or (E)-methyl 2-phenyl-2-[3-(phenylimino)isobenzofuran-1(3H)-ylidene]acetate 2 (136.8 mg, 55\%).

(E)-methyl 2-[3-(butylimino)isobenzofuran-1(3H)-ylidene]acetate (1). Colorless solid, mp 106-107 ${ }^{\circ} \mathrm{C}$. IR (KBr ): $v=2957$ (m), 2932 (m), $2873(\mathrm{w}), 1687$ (m), 1646 (s), 1582 (s), 1459 (m), 1402 (m), $1316(\mathrm{w})$, $1221(\mathrm{~m}), 1142(\mathrm{~m}), 768(\mathrm{~m}) \mathrm{cm}^{-1} ;{ }^{1} \mathrm{H}-\mathrm{NMR}$ (300 MHz, $\left.\mathrm{CDCl}_{3}\right): \delta=9.09-9.00(\mathrm{~m}, 1 \mathrm{H}), 7.92-7.84$ $(\mathrm{m}, 1 \mathrm{H}), 7.68-7.56(\mathrm{~m}, 2 \mathrm{H}), 5.94(\mathrm{~s}, 1 \mathrm{H}), 3.80(\mathrm{~s}, 3 \mathrm{H}), 3.66(\mathrm{t}, J=7.2,2 \mathrm{H}), 1.78-1.61(\mathrm{~m}, 2 \mathrm{H})$, $1.52-1.37(\mathrm{~m}, 2 \mathrm{H}), 0.97$ (t, $J=7.3,3 \mathrm{H}) ;{ }^{13} \mathrm{C}-\mathrm{NMR}\left(75 \mathrm{MHz}, \mathrm{CDCl}_{3}\right): \delta=167.0,161.8,152.8,133.7$, 132.6, 132.1, 132.0, 127.7, 122.6, 96.6, 51.5, 47.9, 32.9, 20.6, 13.9; GC-MS: $m / z=259(35)\left[\mathrm{M}^{+}\right]$, 228 (13), 200 (100), 186 (29), 184 (26), 172 (29), 159 (44), 158 (83), 130 (41), 102 (16), 89 (18); anal. calcd for $\mathrm{C}_{15} \mathrm{H}_{17} \mathrm{NO}_{3}$ (259.30): C, 69.48; H, 6.61; N, 5.40; found C, 69.50; H, 6.58; N, 5.39.

(E)-methyl 2-phenyl-2-[3-(phenylimino)isobenzofuran-1(3H)-ylidene]acetate (2). Yellow solid, mp 56-57 ${ }^{\circ} \mathrm{C}$; IR (KBr): $v=3019(\mathrm{w}), 1712(\mathrm{~s}), 1691(\mathrm{~s}), 1613(\mathrm{~m}), 1590(\mathrm{~m}), 1489(\mathrm{w}), 1300(\mathrm{w}), 1268(\mathrm{w})$, 1216 (m), 1053 (s), 1006 (m), 757 (s), 692 (w) cm ${ }^{-1} ;{ }^{1} \mathrm{H}-\mathrm{NMR}\left(300 \mathrm{MHz}, \mathrm{CDCl}_{3}\right): \delta=8.29$ (d, $J=7.1$, $1 \mathrm{H}), 8.07-8.02(\mathrm{~m}, 1 \mathrm{H}), 7.68-7.57$ (m, $2 \mathrm{H}), 7.50-7.43$ (m, $2 \mathrm{H}), 7.43-7.28$ (m, $5 \mathrm{H}), 7.26-7.19$ (m, $2 \mathrm{H}), 7.15-7.07(\mathrm{~m}, 1 \mathrm{H}), 3.89(\mathrm{~s}, 3 \mathrm{H}) ;{ }^{13} \mathrm{C}-\mathrm{NMR}\left(75 \mathrm{MHz}, \mathrm{CDCl}_{3}\right): \delta=167.8,153.3,151.8,144.5$, 134.1, 134.0, 132.4, 132.2, 131.2, 129.5, 128.6, 128.2, 127.9, 125.5, 125.2, 124.9, 123.7, 112.7, 52.5; GC-MS: $m / z=355(36)\left[\mathrm{M}^{+}\right], 324$ (16), 296 (100), 295 (46), 267 (21), 246 (5), 219 (5), 190 (7), 165 (7), 77 (16); anal. calcd for $\mathrm{C}_{23} \mathrm{H}_{17} \mathrm{NO}_{3}$ (355.39): C, 77.73; H, 4.82; N, 3.94; found C, 77.71; H, 4.85; N, 3.90 . 


\subsection{Seedlings Growth Bioassay}

Arabidopsis thaliana L. (Heyn.) seeds, ecotype Columbia (Col-0), were surface sterilized for 3 min in EtOH/Triton X-100 (50:0.01), and successively in NaOCl/Triton X-100 (0.5:0.01) solutions for $3 \mathrm{~min}$, then were rinsed three times in sterilized distilled water. To promote the synchronization of the germination, the seeds were vernalized in $0.1 \%$ agar solution at $4{ }^{\circ} \mathrm{C}$ for $48 \mathrm{~h}$, and then fifty seeds were sown in Petri dishes $(100 \mathrm{~mm} \times 150 \mathrm{~mm})$ containing agar $(0.8 \%)$ enriched with Murashige-Skoog medium (from Sigma-Aldrich) and sucrose (1\%). The Petri dishes were then kept in a growth chamber with $8 / 16 \mathrm{~h}$ [light $\left(60 \mu \mathrm{mol} \mathrm{m} \mathrm{s}^{-2} \mathrm{~s}^{-1}\right)$ /darkness] photoperiod, at $22 \pm 2{ }^{\circ} \mathrm{C}$ and $55 \%$ relative humidity for 4 days. To evaluate the effect of each compound on plant growth, six Arabidopsis seedlings (4 days old) were transplanted on Petri dish containing $150 \mathrm{~mL}$ of agarised medium $(0.8 \%)$ enriched with 0 , $50,100,200,400 \mu \mathrm{M}$ of each compound. Both molecules were firstly dissolved in EtOH and then diluted in agarized medium to reach the final concentrations. In Control treatment was added the same amount of ethanol employed to solubilize the molecules.

The seedlings were incubated as previously described for 10 days, and then plant material was sampled for the analyses. Total fresh weight (FW), leaf number (LN), total leaf area (LA) and root morphology were analyzed. In particular, Primary Root Length (PRL), Number of Lateral Root (NLR), Root Hair Length (RHL), and Root Hair Density (RHD) were analyzed through the WinRhizo Pro System v. 2002a software (Instruments Règent Inc., Sainte-Foy-Sillery-Cap-Rouge, Quebec, Canada), after capturing roots image by scanner (Epson Expression 800, Instruments Règent).

\subsection{Measurement of Photosynthetic Pigments}

The total amounts of chlorophyll a, chlorophyll b, and carotenoids were analyzed and calculated according to Wellburn [30]. The pigment content (mg/g of FW) was evaluated according to the following Equations [30]:

$$
\begin{gathered}
C h l_{a}(\mu g)=\left(15.65\left(D O_{666}-D O_{750}\right)-7.34\left(D O_{653}-D O_{750}\right)\right) * V \\
C h l_{b}(\mu g)=\left(27.05\left(D O_{653}-D O_{750}\right)-11.21\left(D O_{666}-D O_{750}\right)\right) * V \\
\left.C t(X+C)(\mu g)=\left(1000\left(D O_{470}-D O_{750}\right)-2.86 C h l_{a}-129.2 C h l_{b}\right) / 221\right) * V
\end{gathered}
$$

In addition, the carotenoid:chlorophyll ratio was calculated as an indicative measurement of the physiological status of the plants [15].

\subsection{Lipid Peroxidation}

The extent of lipid peroxidation was determined on treated seedlings of $A$. thaliana through measuring the amount of malonyldialdehyde (MDA) formation by thiobarbituric acid method as described by Hodges et al. [31]. After treatment, $100 \mathrm{mg}$ of plant material were homogenized in $80 \%$ ethanol and centrifuged at $3,000 \times \mathrm{g}$ for $10 \mathrm{~min}$ at $4{ }^{\circ} \mathrm{C}$, the supernatant was collected, incubated for $25 \mathrm{~min}$ at $95{ }^{\circ} \mathrm{C}$ with $20 \%$ trichloroacetic acid (TCA) containing $0.01 \%$ hydroxytoluenebutylate, with and without $0.5 \%$ thiobarbituric acid (TBA), and quickly cooled in ice for $10 \mathrm{~min}$. The absorbance of the reaction mixture was measured at 450, 532 and $600 \mathrm{~nm}$. The equivalents of MDA (nmol/mL) were calculated based on the following formulae: 


$$
\begin{gathered}
\mathrm{A}=\left[\left(\mathrm{Abs}_{532+\mathrm{TBA}}-\mathrm{Abs}_{600+\mathrm{TBA}}\right)-\left(\mathrm{Abs}_{532-\mathrm{TBA}}-\mathrm{Abs}_{600-\mathrm{TBA}}\right)\right] \\
\mathrm{B}=\left[\left(\mathrm{Abs}_{440+\mathrm{TBA}}-\mathrm{Abs}_{600+\mathrm{TBA}}\right) * 0.0571\right] \\
\text { MDA equivalents }(\mathrm{nmol} / \mathrm{mL})=(\mathrm{A}-\mathrm{B} / 157000) * 10^{6}
\end{gathered}
$$

\subsection{Statistical Analysis}

To evaluate the effects of each molecule a completely random design with five replications was adopted. Data were evaluated for normality (Kolmogorov-Smirnov test) and tested for homogeneity of variances (Levene's test). All parameters were estimated by ANOVA, and Tukey's (for homoscedastic data) or Tamhane's T2 (for heteroscedastic data) test $(p \leq 0.05)$ was applied to compare the statistical significance of differences among group means. All statistical analyses were performed using SPSS ver. 6.1 software (Insightful Corporation, Seattle, WA, USA). The responses of FW, PRL, NLR, RHL and RHD parameters to different doses of both molecules were evaluated by a nonlinear regression model using the Equation (7) for inhibitory effects, or the Equation (8) when stimulatory (hormesis) effects were observed [32,33]:

$$
\begin{gathered}
y=\mathrm{C}+\left\{\mathrm{D}-\mathrm{C} / 1+e^{\wedge}\left[B \ln \left(\mathrm{x} / \mathrm{ED}_{50}\right)\right]\right\} \\
y=\mathrm{C}+\left\{\mathrm{D}-\mathrm{C}+\mathrm{f} * \mathrm{x} / 1+\left[1+\left(2 * \mathrm{f} * \mathrm{ED}_{50} / \mathrm{D}-\mathrm{C}\right)\right] * e^{\wedge}\left[B \ln \left(\mathrm{x} / \mathrm{ED}_{50}\right)\right]\right\}
\end{gathered}
$$

where $\mathrm{C}$ was the expected response at indefinitely large concentrations, $\mathrm{D}$ the control mean response, $f$ the initial rate of increase in response at sub-inhibitory concentration, finally $\mathrm{ED}_{50}$, defined the dose required to reduce $50 \%$ of the total response, where $\mathrm{B}$ was the rate of change around the $\mathrm{ED}_{50}$.

The $\mathrm{ED}_{50}$ data were firstly checked for normality (Kolmogorov-Smirnov test) and tested for homogeneity (Leven Median test). Then, the phytotoxicity comparison between two molecules was performed by one-way ANOVA using the $\mathrm{ED}_{50}$ as a variable and the molecule as main factor. The statistical significance of differences among group means were estimated by Tukey's (homoscedastic data) or Tamhane's T2 (heteroscedastic data) tests $(p \leq 0.05)$.

\section{Conclusions}

Taken together, our results indicate that 3-(methoxycarbonylmethylene)isobenzofuran-1-imines are a promising potential class of novel synthetic herbicides. In particular, (E)-methyl 2-[3(butylimino)isobenzofuran-1(3H)-ylidene]acetate (1) and (E)-methyl 2-phenyl-2-[3-(phenylimino)isobenzofuran-1(3H)-ylidene]acetate (2), synthetized by a catalytic oxidative carbonylation process, are able to induce alterations on plant metabolism at multiple target sites. Both compounds $\mathbf{1}$ and $\mathbf{2}$ showed a strong phytotoxic effect on the shoot as well as the root systems of Arabidopsis seedlings. The two molecules had different effects on root growth, even though a hormonal involvement has been suggested in both cases. It is possible that the effects on the aerial part, similar for both molecules, are due to an indirect effect of the strong alterations on root morphology and anatomy. It is well known that the root system plays a crucial role on nutrient uptake, and an alteration of its function could be responsible for the limited nutrient supply and consequently for shoot form and function. 


\section{Acknowledgments}

Thanks are due to the European Commission, FSE (Fondo Sociale Europeo) and Calabria Region for a fellowship grant to R.M.

\section{Author Contributions}

All the authors contributed equally to this work.

\section{Conflicts of Interest}

The authors declare no conflict of interest.

\section{References}

1. Böger, P., Wakabayashi, K., Hirai, K., Eds.; Herbicide Classes in Development: Mode of Action, Targets, Genetic Engineering, Chemistry; Springer: Berlin, Germany, 2002.

2. Heap, I. International Survey of Herbicide Resistant Weeds. Available online: http://www.weedscience.org (accessed on 21 September 2005).

3. Ryan, G.F. Resistance of common groundsel to simazine and atrazine. Weed Sci. 1970, 18, 614-616.

4. Holt, J.S.; LeBaron, H.M. Significance and distribution of herbicide resistance. Weed Technol. 1990, 4, 141-149.

5. Beckie, H.J. Herbicide-resistant weeds: Management tactics and practices. Weed Technol. 2006, 20, 793-814.

6. Green, J.M. Current State of Herbicides in Herbicide-Resistant Crops. Pest Manag. Sci. 2014, doi:10.1002/ps.3727.

7. Gabriele, B.; Mancuso, R.; Salerno, G. Oxidative carbonylation as a powerful tool for the direct synthesis of carbonylated heterocycles. Eur. J. Org. Chem. 2012, 2012, 6825-6839.

8. Gabriele, B.; Salerno, G.; Costa, M. Oxidative Carbonylations. Top. Organomet. Chem. 2006, 18, 239-272.

9. Gabriele, B.; Costa, M.; Salerno, G.; Chiusoli, G.P. An efficient and selective palladium-catalysed oxidative dicarbonylation of alkynes to alkyl- or aryl-maleic esters. J. Chem. Soc. Perkin Trans. 1 1994, 1, 83-87.

10. Veluri, R.; Weir, T.L.; Bais, H.P.; Stermitz, F.R.; Vivanco, J.M. Phytotoxic and antimicrobial activities of catechin derivatives. J. Agric. Food Chem. 2004, 52, 1077-1082.

11. Baziramakenga, R.; Simard, R.R.; Leroux, G.D. Effects of benzoic and cinnamic acids on growth, mineral composition, and chlorophyll content of soybean. J. Chem. Ecol. 1994, 20, 2821-2833.

12. Einhellig, F.A.; Reigosa, M.J.; Pedrol, N. The physiology of allelochemical action: Clues and views. In Allelopathy: From Molecules to Ecosystems; Reigosa, M.J., Pedrol, N., Eds.; Science Publishers: Enfield, NH, USA, 2002; pp. 1-23.

13. Graña, E.; Sotelo, T.; Díaz-Tielas, C.; Reigosa, M.J.; Sánchez-Moreiras, A.M. The phytotoxic potential of the terpenoid citral on seedlings and adult plants. Weed Sci. 2013, 61, 469-481. 
14. Djordjevic, D.; Cercaci, L.; Alamed, J.; McClements, D.J.; Decker, E.A. Stability of citral in protein-and gum arabic-stabilized oil-in-water emulsions. Food Chem. 2008, 106, 698-705.

15. Filella, I.; Serrano, L.; Serra, J.; Penuelas, J. Evaluating wheat nitrogen status with canopy reflectance indices and discriminant analysis. Crop Sci. 1995, 35, 1400-1405.

16. Sánchez-Moreiras, A.M.; Martínez-Peñalver, A.; Reigosa, M.J. Early senescence induced by 2-3H-benzoxazolinone (BOA) in Arabidopsis thaliana. J. Plant Physiol. 2011, 168, 863-870.

17. Liu, J.; Wu, Y.H.; Yang, J.J.; Liu, Y.D.; Shen, F.F. Protein degradation and nitrogen remobilization during leaf senescence. J. Plant Biol. 2008, 51, 11-19.

18. Smith, R.D.; Wilson, J.E.; Walker, J.C.; Baskin, T.I. Protein-phosphatase inhibitors block root hair growth and alter cortical cell shape of Arabidopsis roots. Planta 1994, 194, 516-524.

19. Ishihara, H.; Martin, B.L.; Brautigan, D.L.; Karaki, H.; Ozaki, Y.; Kato, Y.; Fusetani, N.; Watabe, S.; Hashimoto, K.; Uemura, D.; et al. Calyculin A and okadaic acid, inhibitors of protein phosphatases activity. Biochem. Biophys. Res. Commun. 1989, 159, 871-877.

20. Cohen, P.; Holmes, C.F.B.; Tsukitani, Y. Okadaic acid: A new probe for the study of cellular regulation. Trends Biochem. Sci. 1990, 15, 98-102.

21. Eriksson, J.E.; Brautigan, D.L.; Vallee, R.; Olmsted, J.; Fujiki, H.; Goldman, R.D. Cytoskeletal integrity in interphase cells requires protein phosphatase activity. Proc. Natl. Acad. Sci. USA 1992, 89, 11093-11097.

22. Gliksman, N.R.; Parsons, S.F.; Salmon, E.D. Okadaic acid induces interphase to mitotic-like microtubule dynamic instability by inactivating rescue. J. Cell Biol. 1992, 119, 1271-1276.

23. Vandré, D.D.; Wills, V.L. Inhibition of mitosis by okadaic acid: Possible involvement of a protein phosphatase 2A in the transition from metaphase to anaphase. J. Cell Sci. 1992, 101, 79-91.

24. Furutani, I.; Watanabe, Y.; Prieto, R.; Masukawa, M.; Suzuki, K.; Naoi, K.; Thitamadee, S.; Shikanai, T.; Hashimoto, T. The SPIRAL genes are required for directional control of cell elongation in Arabidopsis thaliana. Development 2000, 127, 4443-4453.

25. Sugimoto, K.; Himmelspach, R.; Williamson, R.E.; Wasteneys, G.O. Mutation or drug-dependent microtubule disruption causes radial swelling without altering parallel cellulose microfibril deposition in Arabidopsis root cells. Plant Cell Online 2003, 15, 1414-1429.

26. Ivanchenko, M.G.; Muday, G.K.; Dubrovsky, J.G. Ethylene-auxin interactions regulate lateral root initiation and emergence in Arabidopsis thaliana. Plant J. 2008, 55, 335-347.

27. Li, X.; Gruber, M.Y.; Hegedus, D.D.; Lydiate, D.J.; Gao, M.J. Effects of a coumarin derivative, 4-methylumbelliferone, on seed germination and seedling establishment in Arabidopsis. $J$. Chem. Ecol. 2011, 37, 880-890.

28. Laskowski, M.; Grieneisen, V.A.; Hofhuis, H.; Colette, A.; Hogeweg, P.; Marée, A.F.; Scheres, B. Root system architecture from coupling cell shape to auxin transport. PLoS Biol. 2008, 6, e307.

29. Mancuso, R.; Ziccarelli, I.; Armentano, D.; Marino, N.; Giofrè, S.V.; Gabriele, B. Divergent palladium-catalyzed multicomponent carbonylative approaches to functionalized isoidolinone and isobenzofuranimine derivatives. J. Org. Chem. 2014, 79, 3506-3518.

30. Wellburn, A.R. The spectral determination of chlorophylls a and b, as well as total carotenoids, using various solvents with spectrophotometers of different resolution. J. Plant Physiol. 1994, 144, 307-313. 
31. Hodges, D.M.; DeLong, J.M.; Forney, C.F.; Prange, R.K. Improving the thiobarbituric acid-reactive-substances assay for estimating lipid peroxidation in plant tissues containing anthocyanin and other interfering compounds. Planta 1999, 207, 604-611.

32. Streibig, J.C.; Kudsk, P.; Jensen, J.E. A general joint action model for herbicide mixtures. Pestic. Sci. 1998, 53, 21-28.

33. Belz, R.G.; Hurle, K.; Duke, S.O. Dose-response a challenge for allelopathy? Nonlinearity Biol. Toxicol. Med. 2005, 3, 173-211.

Sample Availability: Samples of the compounds $\mathbf{1}$ and $\mathbf{2}$ are available from the authors.

(C) 2014 by the authors; licensee MDPI, Basel, Switzerland. This article is an open access article distributed under the terms and conditions of the Creative Commons Attribution license (http://creativecommons.org/licenses/by/3.0/). 